\title{
Competencia mediática \\ en la etapa infantil en España
}

Media Competence in Children from Spain

Compétence médiatique chez les enfants en Espagne

Competência mediática na etapa infantil na Espanha

Fecha de recepción: 18 DE MARZO DE 2015/Fecha de aceptación: 26 DE MAYO DE 2017/Fecha de disponibilidad en línea: 1 DE DICIEMBRE DE 2017

Encuentre este artículo en http://magisinvestigacioneducacion.javeriana.edu.co/

Pablo Maraver-López

UnIVERSIDAD DE HUELVA

Huelva, España

pablo.maraver@dedu.uhu.es

Isidro Marín-GutiérRez

Universidad Técnica Particular de Loja

LOJA, ECUAdOR

imarin1@utpl.edu.ec

\section{Resumen}

Este artículo de investigación muestra los resultados de una investigación sobre competencia mediática de niños españoles de 4,5 y 6 años. El objetivo principal es analizar el nivel de competencia mediática que alcanzan los niños de infantil en cada una de las dimensiones que la componen. En concreto, estas dimensiones son: lenguaje, tecnología, procesos de interacción, procesos de producción y difusión, estética e ideología y valores. La población de estudio corresponde a 274 niños y niñas de 4, 5 y 6 años de edad. Los resultados obtenidos indican los distintos niveles de competencia que los niños alcanzan en cada una de las dimensiones analizadas.

\section{Palabras claves}

Competencia; infancia; educación sobre medios

de comunicación; alfabetización; encuesta

Para citar este artículo / To cite this article / Pour citer cet article / Para citar este artigo

Caldeiro-Pedreira, Mari Carmen; Maraver-López, Pablo \& Marín-Gutiérrez, Isidro (2017). Competencia mediática en la etapa infantil en España.

magis, Revista Internacional de Investigación en Educación, 10 (20), 35-48. https://doi.org/10.11144/Javeriana.m10-20.cmei 
Keywords

Competition; childhood;

media education; literacy; survey

\section{Mots clés}

Compétence; enfance; éducation aux medias de communication;

alphabétisation; enquête

\section{Abstract}

This article presents the results of a research on the media competence of Spanish children of 4-6 years old. The main objective is to analyze the level of media competence that boys and girls have in each of the dimensions that compose it. Specifically, these dimensions are: language, technology, interaction processes, production and dissemination processes, aesthetics, ideology and values. The study is composed by 274 boys and girls of 4-6 years. Results indicate the different levels of competence that boys and girls reach in each of the analyzed dimensions.

\section{Résumé}

Cet article de recherche montre les résultats d'une recherche par rapport à la compétence médiatique chez les enfants espagnols de 4-6 ans. L'objectif principal est celui d'analyser le niveau de compétence médiatique que les filles et les garçons d'éducation infantile réussissent dans chacune des dimensions qui la composent. Notamment; ces dimensions sont: langage, technologie, processus d'interaction, processus de production et diffusion, esthétique, idéologie et valeurs. La population d'étude corresponde à 274 garçons et filles de 4-6 ans. Les résultats obtenus indiquent les différents niveaux de compétences que les enfants réussissent dans chacune des dimensions analysées.

\section{Palavras-chave}

Competência; infância; educação

sobre meios de comunicação;

alfabetização; questionário

\section{Resumo}

Este artigo mostra os resultados de uma pesquisa que tem como objetivo principal analisar o nível de competência mediática de crianças de educação infantil em dimensões como linguagem, tecnologia, processos de interação, processos de produção e difusão, estética, ideologia e valores. A população de estudo corresponde a 274 crianças. Os resultados obtidos indicam os diferentes níveis de competência que as crianças atingem em cada uma das dimensões analisadas. 


\section{Introducción}

El alcance de una ciudadanía alfabetizada trasciende fronteras nacionales y centra el interés del Parlamento y la Comisión Europea en los últimos años. En el ámbito nacional, los ecos son representativos y hay investigaciones como la realizada por Alba Ambròs-Pallarès y Ramón Breu-Pañella (2011) que muestran algunas ideas para el establecimiento de sinergias entre los medios y la educación formal y no formal. Además, focalizan su interés elementos clave tales como la creatividad, el desarrollo de la actitud crítica o la necesidad de formación cognitiva y axiológica que contribuya al buen uso de los medios y tecnologías de la comunicación.

En este sentido, destaca el estudio de Julio Cabero-Almenara, Verónica Martín-Díaz y María del Carmen Llorente-Cejudo (2012) que tiene como precedente, entre otros el de Martín Rodríguez-Rojo (2003), con el que comparte un interés común: la elaboración y exposición de buenas prácticas. En la misma línea se sitúan estudios como el de José Ignacio Aguaded-Gómez (2009), que focaliza su atención en las buenas prácticas de teleinformación en la universidad. Así mismo, Elvira Mifsud-Talon (2012) desarrolla buenas prácticas TIC en el contexto familiar y docente. Unos y otros han tratado de elaborar manuales que recojan conductas que apuestan por la formación y desarrollo de la autonomía mediática, en especial la del menor. Conforme indican Montserrat Castellana-Rosell, Xavier Sánchez-Carbonell, Carla Graner-Jordana y Marta Beranuy-Fargues (2007), las estrategias educativas referidas al uso de los móviles, los videojuegos o internet adquieren un valor trascendental, dado que son algunas de las formas de comunicación más utilizadas por los menores. Los contenidos emitidos por unos y otros influyen de forma importante sobre la conformación de la identidad de los usuarios y sobre la construcción de su escala de valores. Con el fin de intervenir en tal repercusión y poder mediatizarla, los autores incluyen en su trabajo diferentes actuaciones preventivas para mejorar el uso del móvil o de los videojuegos, desde el punto de vista de los valores. En este contexto se sitúa el objetivo de este artículo que consiste en analizar las respuestas que los niños de educación infantil señalan sobre contenidos relacionados con las dimensiones que componen la competencia mediática. La investigación se cierra con una descripción de los principales recursos educativos que se han elaborado sobre la competencia mediática en el contexto español. Finalmente, los resultados obtenidos servirán como referente para el diseño de nuevas propuestas que mejoren el nivel de competencia mediática de los niños de educación infantil.

\section{Marco teórico}

La vertiginosidad con la que se desarrolla la comunicación y la instantaneidad de las comunicaciones requieren una ciudadanía bien formada, capaz de sobrevivir en la "sociedad del espectáculo" Jean Baudrillard (1974) o Román Gubern (2000).

El surgimiento exponencial de la información y las imágenes y el contacto con estas no suponen su comprensión ni el desarrollo de la habilidad que permite al sujeto analizarlas y protegerse ante los posibles efectos adversos que puedan derivarse de estas.

Para ello es necesario el desarrollo de la capacidad que permita a personas de cualquier edad su detección y la facultad para analizar y contrastar la información e imágenes a las que acceden. Esta necesidad se acentúa en el caso de los niños, quienes, cada vez a edades más tempranas
Descripción del artículo | Article description | Description de l'article Artigo descrição

Este artículo de investigación se ha realizado dentro del proyecto La enseñanza obligatoria ante la competencia en comunicación audiovisual en un entorno digital (EDU2010-21395-C03-03), enmarcado en la Convocatoria de I+D del Ministerio de Economía, Industria y Competitividad, de España, y en el proyecto de investigación de excelencia La competencia audiovisual de la ciudadanía andaluza. Estrategias de alfabetización mediática en la sociedad del ocio digital, de la Junta de Andalucía (SEJ5823-2010) 
(desde los cuatro años), según indica Pedro Reinares-Lara (2010), simultanean el uso de internet con el consumo de programación televisiva.

Desde 2010, la población de 0-14 años en España ronda el 30\% del total; en cuanto al número de escolares, según publicó en su informe el Ministerio de Educación, Cultura y Deporte, MECD (2012), el alumnado de infantil creció 2,1\%, lo que sitúa a España en torno a 1.954.000 estudiantes, alrededor de 41.000 más que en cursos anteriores. En el caso que nos ocupa, el alumnado de infantil se repartió en 21.000 centros públicos, privados y concertados. De este total, en torno al $69 \%$ cursó sus estudios en instituciones educativas públicas y el $31 \%$ restante en centros privados o concertados, según reflejan los datos del mencionado informe.

Estos escolares, según indica el Observatorio Nacional de las Telecomunicaciones y de la Sociedad de la Información, ONTSI (2015), cuentan en los hogares con diferentes dispositivos tecnológicos que los padres y madres adquieren, pero no utilizan. El horario laboral, las ocupaciones propias de la vida diaria o la falta de conocimientos por parte de las familias son algunos de los principales motivos que favorecen la proliferación de las "nanis digitales", terminología adoptada para referirse al uso, en ocasiones abusivo que los menores ejercen de las TIC. El estudio de Eurodata TV Worldwide, presentado en 2013, confirma esta afirmación cuando señala que la pantalla del televisor ocupa la mirada de los niños de entre 4 y 12 años durante unas 2 horas y 20 minutos al día. Esta cifra es excesivamente elevada, si tenemos en cuenta que se trata de una única ventana de las múltiples que componen el contexto mediático. Por otra parte, los smartphones llegan a la vida de los menores a edades cada vez más tempranas; así mismo, los ordenadores portátiles o las tablets se instauran como una herramienta fundamental y determinante para entretener al público infantil y a los adolescentes principalmente. En todo caso, el mayor número de dispositivos y el creciente número de horas que el usuario invierte no garantizan el desarrollo de la actitud crítica, conforme indica José Ignacio Aguaded-Gómez (2009).

Si a estos datos añadimos la falta de conocimientos tecnológicos que buena parte de los padres y madres confiesan, el resultado es abrumador. Las cifras de ciberbullying o la difusión incontrolada de imágenes comprometidas son algunas de las características del ecosistema mediático al que Roxana Morduchowicz, Atilio Marcón y Paula Camarda (2006) denominan "ecosistema comunicativo".

La realidad demuestra que un niño puede enseñar a sus progenitores a configurar un teléfono móvil y es capaz de navegar por diferentes webs con naturalidad y soltura. Sin embargo, hay una marcada carencia de investigaciones que implementen nuevas prácticas y sirvan como germen de estrategias adecuadas para empoderar a los analfabetos digitales y formarlos para que alcancen la "autonomía mediática" (Gozálvez, 2013) que les permita actuar de forma crítica e independiente.

Esta situación demanda, de forma inminente, la alfabetización de la ciudadanía mediática. Así, la alfabetización comunicativa y la competencia mediática para el desarrollo de la actitud crítica deben iniciarse en las etapas inferiores de la vida del sujeto, si bien continúan a lo largo de toda la vida. Por tanto, se alude al "life long learning", definido por la Organización de las Naciones Unidas para la Educación, la Ciencia y la Cultura, UNESCO, y para el cual han diseñado diversas estrategias que permiten a la ciudadanía desarrollar las habilidades necesarias para desarrollar su vida en el entorno tecnológico actual.

La formación ha de centrarse de modo especial en los niños, dado que ellos, por su edad, poseen un menor nivel de desarrollo cognitivo y 
también axiológico. Por otra parte, siguiendo a Rosa Julia Guzmán y Mónica Guevara (2010), en las edades inferiores se establecen "las bases del desarrollo del individuo y por ende, de la sociedad". Los menores - como indica Elisabel Rubiano-Albornoz (2010, p. 301) - "son personas completas, con condiciones para aprender y enseñar, portadores de saberes, haceres y sentires producto de la particularidad individual y social de cada uno, con opiniones y deseos propios". Pese a ello y siguiendo a Guzmán y Guevara (2010), es necesaria su alfabetización no solo en el campo del lenguaje sino también en el ámbito del significado que se deriva de los mensajes audiovisuales. Esta formación les permitirá, conforme afirma José Antonio Marina (2006), convertirse en una ciudadanía libre y autónoma. La primera condición para que esta se lleve a cabo es el abandono de la pasividad que está directamente relacionada con la adquisición de las habilidades que hacen posible la percepción del mensaje y su comprensión. Esta definición se identifica con el "prosumer", terminología utilizada, entre otros, por Michael Dezuanni y Andrés Monroy-Hernández (2012) y que ha sido adoptada por Jacqueline Sánchez-Carrero y Paloma Contreras-Pulido (2012). Todo ello responde, como indica Mari Carmen Caldeiro-Pedreira (2014), en su tesis doctoral, a la definición de "consumidores de información que cuentan con los conocimientos que les permiten reelaborar productos mediáticos que no vulneren los principios legislativos ni morales" (Caldeiro-Pedreira, 2014, p. 114). El cumplimiento de este objetivo requiere la adecuada alfabetización entendida —siguiendo las recomendaciones de la Comisión y del Parlamento Europeo-como la capacitación crítica que permite al receptor adoptar la actitud de "emirec" (EMIsor-RECeptor), término al que se ha referido Henry Jenkins (2008).

En relación con la alfabetización, las mencionadas instituciones europeas destacan la necesidad de incluir la educación mediática en el currículo académico correspondiente a las diferentes etapas formativas. De este reclamo se hacen eco diferentes asociaciones como Acción Educativa (2005), con una investigación en la que ofrece propuestas para la integración de las TIC y los medios en la educación en el marco de la entonces vigente Ley Orgánica Educativa (LOE, 2006).

Tanto la iniciativa legislativa como las propuestas hechas hasta el momento comparten un origen común situado en el desarrollo de la competencia audiovisual.

Este artículo se ha diseñado siguiendo la definición de competencia audiovisual realizada por Joan Ferrés-Prats (2006). El autor establece seis dimensiones que conforman la mencionada competencia. En concreto, se trata de la dimensión de los lenguajes, tecnología, procesos de interacción, procesos de producción y difusión, ideología y valores, y estética.
Tal competencia guarda estrecha relación con la competencia comunicativa definida, entre otros autores por Josefina Prado-Aragonés (2001). A su vez, esta última - junto con la audiovisual- constituye la base sobre la que se forja la competencia mediática cuyas dimensiones e indicadores han perfilado, entre otros, María Amor Pérez-Rodríguez y Águeda Delgado-Ponce (2012).

La competencia mediática adquiere gran importancia en la educación infantil dado que se concibe como aquella habilidad que permite al sujeto interactuar, conocer y comprender la información a la que se accede. Esta afirmación se vincula con la que emiten Isidro Marín-Gutiérrez, Elena Díaz-Pareja y José Ignacio Aguaded-Gómez (2013, p. 45) cuando justifican "la necesidad de un aprendizaje consciente y crítico". Resulta especialmente importante alcanzar este objetivo en el caso de los más pequeños que deben convertirse, siguiendo a Rosa García-Ruiz y Ana Castro-Zubizarreta (2014, p. 45) en "ciudadanos críticos, capaces de manejar información, comprender su sentido y significado". Pese a la necesidad de capacitación desde los niveles y etapas educativas inferiores, en la normativa que regula la etapa de educación infantil se detecta una deficiente presencia explícita de los contenidos audiovisuales si bien, como señalan las mencionadas autoras, es necesario implementarlos en el aula con el fin de empoderar a los niños para recibir y emitir mensajes de forma crítica. Esta introducción corresponde —según indican Ángel Hernando-Gómez y Pablo Maraver-López (2014) - al profesorado, que debe ser capaz de "integrar de manera particular y adaptada a sus necesidades y las de sus alumnos y alumnas los aspectos referidos a la pedagogía, la tecnología y el contenido" (Hernando-Gómez \& Maraver-López, 2014, p. 61). Por otra parte, la formación del niño se justifica por el conjunto de afirmaciones que equiparan la infancia a un período en el cual se desarrolla una construcción de carácter social y cultural adscrita a un lapso más o menos concreto en el cual resulta fundamental la influencia de los medios y sus contenidos.

\section{Metodología}

En este estudio se analizan los datos del cuestionario sobre competencia mediática en educación infantil. Esta investigación se enmarca en la metodología empírico-analítica e indaga sobre el nivel de desarrollo de las dimensiones que componen la competencia mediática que los niños de educación infantil poseen. Para ello se utiliza un cuestionario online diseñado ad hoc, para la etapa de educación infantil. Entre los objetivos de este artículo está descubrir diferencias en competencias mediáticas entre niños y niñas y analizar 
si hay diferencias en competencias mediáticas respecto al tipo de centros educativos. Las hipótesis de partida prevén diferencias entre niños y niñas y una ausencia de diferencias entre los centros educativos en materia de competencias mediáticas.

Las variables dependientes de este estudio se configuran en torno a las seis dimensiones de la competencia mediática establecidas por Joan Ferrés-Prats (2007): lenguajes, tecnología, procesos de interacción, procesos de producción y difusión, ideología y valores, y estética.

El cuestionario fue diseñado a partir del ya elaborado por los miembros del proyecto Competencia mediática. Investigación sobre el grado de competencia de la ciudadanía en España, en el que intervinieron representantes de 17 universidades de España. El procedimiento de validación del instrumento se encuentra en Rosa García-Ruiz, Ana María Duarte-Hueros y Sonsoles Guerra-Liaño (2014).

La aplicación online del cuestionario se realizó simultáneamente en 40 centros educativos, pertenecientes a las diez provincias participantes, que fueron seleccionados en función de su disponibilidad, su titularidad y la conexión a internet. Se ha contado siempre con la presencia de investigadores en las aulas, que han ayudado a los pequeños en la lectura de las preguntas con muchas imágenes y en algunos casos, con el manejo del ordenador. Esto choca con el hecho de que son nativos digitales y refuerza la necesidad de formación tanto tecnológica como axiológica.

Tras la aplicación del cuestionario se generó la base de datos y se procedió a su codificación. Finalmente, las respuestas fueron recategorizadas con el programa estadístico SPSS (v.18), de acuerdo con la rúbrica de evaluación elaborada previamente durante el diseño.

\section{El instrumento}

El instrumento utilizado es el cuestionario de evaluación para la competencia mediática en infantil (García-Ruiz, Duarte-Hueros \& Guerra-Liaño, 2014), alojado en la página web http://goo.gl/k665yE. Consta de una serie de actividades que los niños y niñas de 4, 5 y 6 años han de realizar con la ayuda de una persona adulta.

A continuación, se presentan los ítems del cuestionario y el gráfico 1 con las dimensiones y sus ítems.

- Los primeros cinco ítems corresponden a aspectos identificadores de la muestra, como la edad, sexo, provincia y datos sobre el centro educativo participante. En los ítems 8 y 9 se presenta el video de un anuncio de un producto lácteo. Se pidió a los niños que identificaran por qué les había gustado o no.

- En el ítem 10, se ofrecen una serie de iconos a partir de los cuales deben seleccionar la acción correspondiente: 1. Poner una película, 2. Ir adelante, 3. Ir hacia atrás y 4. Parar.

- Los ítems 11 y 12 presentan dos imágenes de un mismo niño, pero uno de ellos se presenta con un tono azulado. El alumnado debe señalar aquella imagen que mejor represente la siguiente frase: El niño está triste; además de tres posibles respuestas que justifiquen el motivo de su elección.

- El ítem 13 ofrece una serie de aparatos tecnológicos, y los niños han de señalar si los han utilizado en alguna ocasión. Mientras que en el ítem 14, se presentan imágenes de juegos didácticos interactivos para el público infantil, a partir de las cuales deben señalar si los han utilizado. 
- Las preguntas 15 y 16 son de respuesta abierta en la que el alumnado escribe a qué juegan con el ordenador en el colegio, y también en casa.

- Las preguntas 17 y 18 tratan sobre la televisión. En el primer gráfico se ofrecen imágenes de programas televisivos que se emiten en el momento de la encuesta. El alumnado debe señalar cuáles están dirigidas a los niños y cuáles son programas para adultos. Y por último, se les pregunta qué programas de televisión no les permiten ver sus padres, con opción de respuesta abierta.

Gráfico 1

Matriz de análisis: dimensiones y actividades o ítems

\begin{tabular}{l|l|l|l|l|l|l}
\hline & Lenguajes & Tecnología & $\begin{array}{l}\text { Recepción/ } \\
\text { Interacción }\end{array}$ & $\begin{array}{l}\text { Producción/ } \\
\text { Difusión }\end{array}$ & $\begin{array}{l}\text { Ideología/ } \\
\text { Valores }\end{array}$ & Estética \\
\hline Actividad 6 & & & & & & \\
\hline Actividad 7 & & & & & & \\
\hline Actividad 8 & & & & & & \\
\hline Actividad 9 & & & & & & \\
\hline Actividad 10 & & & & & & \\
\hline Actividad 11 & & & & & & \\
\hline Actividad 12 & & & & & & \\
\hline Actividad 13 & & & & & & \\
\hline Actividad 14 & & & & & & \\
\hline Actividad 15 & & & & & & \\
\hline Actividad 16 & & & & & & \\
\hline Actividad 17 & & & & & & \\
\hline Actividad 18 & & & & & & \\
\hline \hline
\end{tabular}

Fuente: elaboración propia

Describimos en el gráfico 1, la matriz de análisis y la relación de cada una de las preguntas del cuestionario con cada una de las dimensiones del marco teórico diseñado por Joan Ferrés-Prats (2006) sobre competencia mediática. Rosa García-Ruiz, Ana María Duarte-Hueros y Sonsoles Guerra-Liaño (2014) describieron concienzudamente este instrumento que hemos utilizado.

\section{Los participantes}

La muestra está constituida por 274 niños y niñas de 40 centros educativos pertenecientes a diez provincias españolas, repartidas por todo el territorio nacional: Cantabria, Córdoba, Granada, Huelva, La Rioja, Lugo, Málaga, Murcia, Sevilla y Valencia. Los escolares pertenecen al tercer curso del segundo ciclo de educación infantil (5-6 años). El 50,7\% de la muestra corresponde a niñas, mientras que el $49,3 \%$ es de niños. En relación con el tipo de centro en el que están escolarizados, el 36\% del alumnado 
pertenece a centros públicos, mientras que el 55\% está escolarizado en centros concertados y el $9 \%$ en centros privados de enseñanza. Concretamente, la muestra, no probabilística e intencionada, queda distribuida como refleja la tabla 1.

Tabla 1

Distribución de la muestra según provincia de procedencia

\begin{tabular}{l|c|c}
\hline Provincias & Número & Porcentaje (\%) \\
\hline Cantabria & 25 & 9,1 \\
\hline Córdoba & 28 & 10,2 \\
\hline Granada & 25 & 9,1 \\
\hline Huelva & 25 & 9,1 \\
\hline La Rioja & 25 & 9,1 \\
\hline Lugo & 25 & 9,1 \\
\hline Málaga & 25 & 9,1 \\
\hline Murcia & 26 & 9,5 \\
\hline Sevilla & 44 & 16,1 \\
\hline Valencia & 26 & 9,5 \\
\hline Total & 274 & 100 \\
\hline \hline
\end{tabular}

Fuente: elaboración propia

\section{Resultados}

Los resultados que se ofrecen a continuación pretenden dar respuesta al objetivo de nuestro estudio, a partir de los datos derivados de los cuestionarios aplicados. En primer lugar, se presentan comparaciones de medias en función de las variables sexo, tipo de centro educativo y provincia. Posteriormente, se analizan las puntuaciones globales del cuestionario. Tras ello, se constatan los resultados obtenidos en cada dimensión del instrumento y finalmente, se hace un análisis correlacional de las dimensiones.

Según el análisis estadístico para la comparación de medias, el nivel de competencia mediática no presenta diferencias significativas en la comparación entre niños y niñas ( $>.05$ en prueba $t$ ), por lo que no podemos considerar que el sexo sea una variable que influya sobre la variable dependiente.

Al comparar las puntuaciones obtenidas en función del tipo de centro en el que el alumnado está escolarizado, sí se han obtenido diferencias significativas ( $<.05$ en prueba $t)$ : las puntuaciones más altas están en los centros privados (mean $=19,80)$ frente a los centros públicos (mean $=$ 18,40) y concertados (mean $=18,22$ ).

También hay diferencias significativas $(<.05$ en prueba $t)$ en función de las provincias. La puntuación media más elevada se recoge en las provincias de Granada y Sevilla con 19,80 puntos, que sitúan la puntuación media de ambas provincias en el nivel excelente, mientras que otras provincias obtienen las menores puntuaciones y se sitúan en el nivel aceptable.

Al analizar los resultados totales sobre el nivel de competencia mediática, se han obtenido las siguientes puntuaciones totales en función de los criterios de evaluación del instrumento que considera que una puntuación de entre 23 y 26 puntos corresponde a un nivel de competencia mediática 
máximo; una puntuación de 19-22 puntos es excelente; de 14-18 puntos aceptable y una puntuación inferior a 13 puntos corresponde a un nivel mínimo.

De este modo, se concluye la siguiente distribución sobre el nivel de competencia mediática presente en la muestra analizada en la que más de la mitad supera el nivel excelente (tabla 2).

Tabla 2

Nivel general de competencia mediática

\begin{tabular}{l|c|c}
\hline & Frecuencia & Porcentaje (\%) \\
\hline Mínimo & 9 & 3,3 \\
\hline Aceptable & 122 & 44,5 \\
\hline Excelente & 126 & 46,0 \\
\hline Máximo & 17 & 6,2 \\
\hline Total & 274 & 100 \\
\hline
\end{tabular}

Fuente: elaboración propia

A continuación, se desglosan los resultados según las seis dimensiones que componen la competencia mediática anteriormente explicadas, a partir de las respuestas del alumnado infantil que ha respondido a los cuestionarios.

\section{Los resultados de competencias mediáticas por dimensiones}

\section{Dimensión de lenguaje}

Esta dimensión hace referencia al conocimiento que posee el alumnado de educación infantil con respecto a los códigos del lenguaje audiovisual y la capacidad de utilizarlos para comunicarse; a la capacidad de analizar los mensajes audiovisuales, según su sentido y significado, estructura narrativa, categoría y sexo; y a la capacidad para construir una narración visual, respetando las reglas del lenguaje visual.

En esta dimensión, los datos arrojan una puntuación media de 5,69. El 50,7\% de los estudiantes ha puntuado 5 o menos sobre los 8 puntos posibles para esta dimensión. En esta dimensión destaca la actividad 7 en la que los participantes debían señalar las caras que representan las emociones de tristeza, alegría, sorpresa y enfado. El $77 \%$ de los niños y las niñas señaló correctamente todas las emociones representadas por los emoticonos.

\section{Dimensión de tecnología}

La dimensión tecnología hace referencia al conocimiento del funcionamiento de las herramientas utilizadas en comunicación audiovisual y digital, y la capacidad de uso de las mismas para poder comunicarse y llegar a comprender cómo se elaboran los mensajes. En esta dimensión, la puntuación media alcanzada es 3,59 puntos. Estos resultados nos muestran que a pesar de los niños de educación infantil manejan aparatos tecnológicos habitualmente, presentan dificultades a la hora de discriminar ciertos aspectos tecnológicos.

En esta ocasión, destaca la actividad 8, en la cual se pregunta sobre un anuncio de televisión realizado por niños. El 67,2\% de las respuestas se centra en el aspecto superficial del contenido, en lugar del aspecto tecnológico. Además, en la actividad 10 debían elegir la acción que corresponde a cada icono (play, pause, avanzar, retroceder). El 27,7\% falla en dos o más iconos, mientras solo el 33,2\% acierta todas y el 39,1\% casi todas.

\section{Dimensión de interacción}

La dimensión interacción hace referencia a la capacidad de identificar las audiencias a las que se dirigen los medios de comunicación y de reconocerse como audiencia activa; a la capacidad de valorar críticamente los elementos emotivos, racionales y contextuales que intervienen en la recepción y valoración de los mensajes audiovisuales; y al conocimiento de la corresponsabilidad social sobre los contenidos que llegan a las audiencias (organismos responsables), y muestran actitudes favorables para servirse de esos organismos. Los datos obtenidos muestran que el nivel de respuestas correctas supera la mitad de la muestra. La puntuación media en esta dimensión ha sido 3,87 puntos de los 6 puntos posibles.

En la actividad 14 tenían que señalar los juegos de ordenador educativos que conocen o utilizan. El $28,5 \%$ de los niños y niñas encuestados manifiesta no utilizar ninguno; el 35\% conoce o utiliza uno o dos juegos; el 22,3\% 3 o 4 juegos y el 14,2\% 5 o 6 juegos educativos. En la actividad 17 debían discriminar si las imágenes pertenecientes a series de televisión corresponden a público mayor o son para niños. El $66 \%$ de los encuestados acierta en el público recomendado para las series de televisión propuestas.

\section{Dimensión de producción y difusión}

Esta dimensión se relaciona con el conocimiento de las funciones y tareas de los responsables de la producción de mensajes; conocimiento de las fases de los procesos de producción y programación de productos audiovisuales; la capacidad para aprovechar los recursos tecnológicos para elaborar mensajes audiovisuales y participar en el entorno comunicativo, que genera una cultura participativa y una actitud responsable. La puntuación media en esta dimensión ha sido 2,30 puntos de los 3 puntos posibles. La actividad 13 cuestiona si ha usado alguna vez uno de estos aparatos tecnológicos. Los resultados indican que el $86 \%$ de la 
muestra utiliza más de 5 aparatos tecnológicos de los 13 aparatos posibles como ordenadores, pizarras digitales, videojuegos, ratón, pantalla, teclado, y posiblemente en casa, teléfono o cámara de fotos.

\section{Dimensión de ideología y valores}

La dimensión de ideología y valores está relacionada con la capacidad de lectura comprensiva y crítica de los mensajes audiovisuales y de los valores éticos, ideológicos y estéticos que transmiten, como representaciones de la realidad. Descubrimos que en educación infantil, los niveles de respuestas correctas respecto al reconocimiento de contenidos sexistas en anuncios publicitarios, se corresponden solo con una cuarta parte de los encuestados. La puntuación media ha sido 7,21 de los 10 puntos posibles. La actividad consiste en indicar si el juguete es para un niño, para una niña o para los dos, el 89,1\% han indicado correctamente la orientación de los distintos juguetes.

\section{Dimensión de estética}

Finalmente, la dimensión estética aglutina la capacidad de analizar, valorar y disfrutar de la innovación formal y temática, y de la educación del sentido estético de los mensajes; la capacidad para formular un juicio estético, valorar un producto audiovisual no solo por lo que cuenta y presenta, sino por la manera como lo cuenta o lo presenta, y la capacidad de establecer comparaciones con otras manifestaciones artísticas: pintura, literatura, música, etc. Los resultados indican que en educación infantil los niños y niñas no han alcanzado la capacidad suficiente para analizar el valor estético de las imágenes, si bien sí responden correctamente a algunas de las cuestiones planteadas, lo que refleja su interés y capacidad para disfrutar de la estética. La puntuación media en esta dimensión ha sido 4,66 puntos de los 6 puntos posibles. La actividad 18 cuestiona sobre los programas de televisión que tienen prohibidos por sus padres: al 26,6\% de los participantes le dejan ver todo, es decir, no hay ningún tipo de filtro ante la televisión. Cabe mencionar que el 51,8\% indica que no juega al ordenador en el colegio frente al 79,2\% que sí juega en el ordenador en casa.

Finalmente, en el análisis correlacional llevado a cabo, hay correlaciones significativas en todas las dimensiones menos en la dimensión ideología y valores, que muestra una correlación negativa con las dimensiones recepción e interacción, y producción y difusión (tabla 3).

Tabla 3

Correlación entre las dimensiones

\begin{tabular}{l|c|c|c|c|c|c}
\hline & Lenguaje & Tecnología & $\begin{array}{l}\text { Recepción e } \\
\text { interacción }\end{array}$ & $\begin{array}{l}\text { Producción } \\
\text { y difusión }\end{array}$ & $\begin{array}{l}\text { Ideología } \\
\text { y valores }\end{array}$ & Estética \\
\hline Lenguaje & 1 &, $132^{*}$ &, $127^{*}$ &, $508^{* *}$ &, $162^{* *}$ &, $136^{*}$ \\
\hline Tecnología &, $132^{*}$ & 1 &, $503^{* *}$ &, $190^{* *}$ &, $341^{* *}$ &, $120^{*}$ \\
\hline Recepción e interacción &, $127^{*}$ &, $503^{* *}$ & 1 &, $223^{* *}$ &,- 091 &, $271^{* *}$ \\
\hline Producción y difusión &, $508^{* *}$ &, $190^{* *}$ &, $223^{* *}$ & 1 &,- 039 &, $138^{*}$ \\
\hline Ideología y valores &, $162^{* *}$ &, $341^{* *}$ &,- 091 &,- 039 & 1 &, $147^{*}$ \\
\hline Estética &, $136^{*}$ &, $120^{*}$ &, $271^{* *}$ &, $138^{*}$ &, $147^{*}$ & 1 \\
\hline \hline
\end{tabular}

* La correlación de Pearson es significativa en el nivel de 0,05 (bilateral).

** La correlación de Pearson es significativa en el nivel de 0,01 (bilateral). 


\section{Limitaciones: más allá de lo utópico}

La realidad social a la que se han referido autores como Jean Baudrillard (1974) o Román Gubern (2000) confirma la necesidad de capacitación por parte de la ciudadanía en general. El interés por alcanzar la autonomía mediática (Caldeiro-Pedreira, 2014) y un nivel de competencia mediática mínimo que faculte para el desarrollo de la vida en la sociedad hipermedia se erigen como núcleos fundamentales hoy.

En este sentido, esta investigación — que busca conocer por dimensiones cuál es el nivel de competencia mediática de los más jóvenes, lejos de presentar o proponer estrategias - centra el interés en el diagnóstico de la situación española. En un contexto con una ingente cantidad de medios y tecnologías que, a priori, podrían conducirnos a pensar que los menores, nativos digitales, desarrollan la dimensión de la tecnología en niveles elevados, arrojan resultados diversos.

Del estudio se deduce la necesidad de capacitación en los ámbitos tecnológicos y en la producción de contenidos; se trata de carencias justificadas, dado el escaso nivel formativo de los usuarios. Los residentes e inmigrantes digitales utilizan las herramientas tecnológicas de forma un tanto intuitiva ya que carecen de una capacitación previa que los dote de los conocimientos mínimos. Tal falencia se sitúa como una limitación fundamental e insta a la administración a ofertar capacitaciones de tal índole. Por otra parte, tampoco se contaba en España con formación sobre producción de contenidos audiovisuales ni análisis crítico de ellos. Todo esto justifica el interés de este estudio que perfila aspectos clave en la sociedad hipermedia actual en la cual priman la digitalización de contenidos y la interactividad. Teniendo en cuenta la utilización del cuestionario online, una de las principales fortalezas ha sido la posibilidad de recoger rápida y simultáneamente muestras de diferentes centros repartidos por todo el territorio nacional.

\section{Conclusiones, discusión final y propuestas de transferencia a la práctica}

Del análisis de los datos obtenidos podemos afirmar que no hay diferencias significativas entre niños y niñas y que sí existen diferencias respecto al tipo de centros educativos con respecto a las competencias mediáticas. Por tanto, se refutan las hipótesis de partida de nuestra investigación. En los centros públicos y concertados se debe trabajar más esta temática. Los resultados obtenidos indican que en educación infantil la mayoría del alumnado es capaz de identificar distintos públicos receptores, por lo que podemos interpretar que dominan correctamente los conocimientos y actitudes ligados a la capacidad de identificar los distintos públicos a los que se dirigen los medios. Por el contrario, el manejo tecnológico para producir nuevos mensajes muestra unos resultados menos satisfactorios. Además, podemos considerar que cualquier niño o niña menor de cinco años ha utilizado, al menos en la escuela, ratón, pantalla, teclado, y posiblemente en casa, teléfono o cámara de fotos y que tras 3 años escolarizados podrían haber utilizado más. Otro aspecto preocupante es la ausencia de filtros y de supervisión parental en el contenido al que más de la cuarta parte de los menores encuestados accede.

Tales precedentes sirven para justificar la necesidad de inclusión de las nuevas formas de comunicación en el contexto formativo y en el aula. Con la introducción de las nuevas y recientes formas de comunicación y la configuración del contexto mediático y comunicativo se confirma la necesaria formación del alumnado infantil. 
Frente a los retos que se presentan, se ofrecen materiales que pueden servir para mejorar los resultados. Así, por ejemplo, pueden aprovecharse recursos que ayuden a conformar el uso correcto del lenguaje utilizado en las conversaciones telemáticas, las aulas virtuales o las conversaciones por correo electrónico con el profesorado. De esta forma, los jóvenes pueden reforzar las posibilidades que las TIC ofrecen al tiempo que se esfuerzan en comunicarse adecuadamente. Además de esto, la presentación de trabajos en formato multimedia y su exposición ante los compañeros puede reforzar la consecución de objetivos de tal índole.

Por otra parte, debido a la creciente implantación de las redes sociales en la vida del internauta, se baraja la posibilidad de que desde los centros educativos se creen grupos en los cuales se intercambie información de un modo supervisado por una persona adulta, situación que puede servir para mediatizar el comportamiento de los usuarios más jóvenes y puede permitirles comunicarse en un ambiente conocido para ellos.

En esta línea contamos con propuestas como la que a lo largo de un curso pasado se ha llevado a cabo en el Proyecto E-Dixgal que consiste en la introducción del libro electrónico en el aula (dimensión tecnología) (Fraga-Varela \& Duarte-Fernández, 2015). Desde las diferentes áreas educativas que conforman la enseñanza obligatoria se introducen las TIC y los dispositivos más recientes como elementos que conforman el ecosistema escolar. Además de incluir los diferentes dispositivos en el aula, hay proyectos que se encargan de fomentar su aprendizaje. No obstante, se aprecia una carencia de actividades que centren el interés en las dimensiones que componen la competencia mediática. Si bien puede considerarse que los mencionados proyectos favorecen el desarrollo y alcance de la dimensión de la tecnología y del lenguaje, resulta fundamental el diseño de buenas prácticas referidas al resto de dimensiones.

Todas las fuentes mencionadas pretenden explorar nuevas formas de enseñar y aprender. Partiendo de los resultados obtenidos en nuestro estudio, se busca además la realización de trabajos que sirvan de guía a los educadores y pretendan la integración de recursos digitales en la escuela.

Así mismo, y entre los trabajos existentes de mayor impacto destacan dos iniciativas, una de ellas denominada Bubuskiski y la otra, El Monosabio (Delgado-Ponce \& Pérez-Rodríguez, 2014). La primera iniciativa está dirigida al público infantil, en ella se trabaja con marionetas con el fin de incidir sobre determinados temas de educomunicación, cuestiones vinculadas con las diferentes dimensiones que conforman la competencia audiovisual y mediática. La segunda corresponde con una serie de monólogos de entre 1 y 2 minutos de duración, para explicar, al igual que en el caso de las marionetas, contenido relacionado con las dimensiones y elementos que componen el contexto audiovisual, como la audiencia y la autoría del contenido o el mensaje, entre otros.

Además de estas iniciativas, y según se ha presentado en el programa La aventura del saber, de Radio Televisión Española, RTVE, sobresale la presencia de dos videos educativos denominados educlips. Este trabajo ha sido realizado por un grupo de estudiantes de comunicación audiovisual en la Universidad Pompeu Fabra. Su finalidad, igual que en los casos anteriores, es explicar alguna de las mencionadas dimensiones como el lenguaje o los receptores del proceso comunicativo (Pérez-Rodríguez, Delgado-Ponce, García-Ruiz \& Caldeiro-Pedreira, 2015). En cualquier caso, la iniciativa sienta precedente y se erige como un referente importante a la hora de - partiendo de los datos analizados- diseñar estrategias adecuadas para el nivel cognitivo estudiado en nuestra investigación.

En definitiva, el presente estudio pretende que los resultados sirvan como referente para el diseño y futura aplicación de estrategias dirigidas a solventar los hándicaps que dificultan el alcance de la competencia mediática. La investigación pretende despertar el interés ante las principales deficiencias detectadas que se han expuesto en el análisis y discusión de este trabajo.

\section{Sobre los autores}

Mari Carmen Caldeiro-Pedreira es doctora en educación y comunicación, Universidad de Huelva. Licenciada con grado en humanidades, Universidad de Santiago de Compostela. Miembro del Grupo Comunicar y de la Red Internacional Alfamed, autora de diversas publicaciones en español e inglés en revistas indexadas y miembro del grupo de investigación Documenta Ecuador.

Pablo Maraver-López es doctorando en ciencias de la educación. Licenciado en psicología. Máster en comunicación y educación audiovisual. Máster universitario en profesorado. Personal investigador bajo el Programa de Formación de Profesorado Universitario (FPU) del Ministerio de Educación, Cultura y Deporte, del gobierno de España. Miembro investigador del grupo de investigación Ágora, Universidad de Huelva.

Isidro Marín-Gutiérrez es licenciado en ciencias políticas y sociología y doctor (PhD) en antropología social, Universidad de Granada. Docente investigador principal, Universidad Técnica Particular de Loja, UTPL, Ecuador. Miembro del consejo técnico de Comunicar, Revista Científica Iberoamericana de Comunicación y Educación. Miembro del grupo de investigación E6, Estudios Sociales e Intervención Social. 


\section{Referencias}

Acción Educativa (2005). Propuestas para la integración de las TIC y los medios de comunicación en la educación en el marco de la Ley Orgánica de la Educación, LOE. Disponible en: https://www. nodo50.org/movicaliedu/manifitic.pdf

Aguaded-Gómez, José Ignacio (2009). El Parlamento Europeo apuesta por la alfabetización mediática. Comunicar, Revista Científica Iberoamericana de Comunicación y Educación, XVI (32), 7-8. Doi: 10.3916/c32-2009-00-001. Disponible en: https://www.revistacomunicar.com/index. php? contenido $=$ detalles $\&$ numero $=32 \&$ articu $\mathrm{lo}=32-2009-01$

Ambròs-Pallarès, Alba \& Breu-Pañella, Ramón (2011). 10 ideas clave. Educar en medios de comunicación. La educación mediática. Barcelona: Graó.

Baudrillard, Jean (1974). La sociedad del consumo. Sus mitos, sus estructuras. Barcelona: Plaza \& Janés.

Cabero-Almenara, Julio; Martín-Díaz, Verónica \& Llorente-Cejudo, María del Carmen (2012). Desarrollar la competencia digital. Educación mediada a lo largo de toda la vida. Sevilla: Eduforma.

Caldeiro-Pedreira, Mari Carmen (2014). Alfabetización comunicativa para el desarrollo de la autonomía moral. Estudio de la competencia mediática de los adolescentes de Lugo (Galicia). Universidad de Huelva. Disponible en: http://rabida.uhu.es/ dspace/handle/10272/9057, http://rabida.uhu. es/dspace/bitstream/handle/10272/9057/Alfa betizacion_comunicativa.pdf?sequence $=2$

Castellana-Rosell, Montserrat; Sánchez-Carbonell, Xavier; Graner-Jordana, Carla \& Beranuy-Fargues, Marta (2007). El adolescente ante las tecnologías de la información y la comunicación: internet, móvil y videojuegos. Papeles del Psicólogo, 28 (3), 196-204. Disponible en: http://www.re dalyc.org:9081/articulo.oa?id=77828306

Delgado-Ponce, Águeda \& Pérez-Rodríguez, María Amor (2014). Bubuskiski la educomunicación para niños. Comunicación y Pedagogía: Nuevas Tecnologías y Recursos Didácticos, 273-274, 86-92.

Dezuanni, Michael \& Monroy-Hernández, Andrés (2012). "Prosumidores interculturales": la creación de medios digitales globales entre los jóvenes. Comunicar, Revista Científica Iberoamericana de Comunicación y Educación, 19 (38), 59-66. Doi: 10.3916/C38. Disponible en: https://www. revistacomunicar.com/index.php?contenido $=$ de talles\&numero $=38 \&$ articulo $=38-2012-08$

España (1980). Ley 4/1980, de 10 de enero, de Estatuto de la Radio y la Televisión, Boletín Oficial del Estado, BOE, 11, 12 de enero de 1980.
Disponible en: https://www.boe.es/buscar/doc. php?id=BOE-A-1980-724

España (2006). Ley Orgánica 2/2006, 3 de mayo, de Educación, Boletín Oficial del Estado, BOE, 106, 4 de mayo de 2006. Disponible en: https://www. boe.es/buscar/act.php?id=BOE-A-2006-7899

Ferrés-Prats, Joan (2006). La competencia en comunicación audiovisual: propuesta articulada de dimensiones e indicadores. Quaderns del CAC, Consell de l'Audiovisual de Catalunya, 25, 9-18. Disponible en: http://www.cac.cat/pfw_files/ cma/recerca/quaderns_cac/Q25ferres2_ES.pdf

Ferrés-Prats, Joan (2007). La competencia en comunicación audiovisual: dimensiones e indicadores. Comunicar, Revista Científica Iberoamericana de Comunicación y Educación, 15 (29), 100-107. Disponible en: https://www.revistacomunicar.com/ verpdf.php?numero $=29 \&$ articulo $=29-2007-17$

Fraga-Varela, Fernando \& Duarte-Fernández, Alba (2015). La perspectiva de las familias de un centro educativo digital con modelo 1 a 1: implantación del Proyecto E-DIXGAL como desarrollo del Plan Escuela 2.0 y el Proyecto Abalar en Galicia. Innovación Educativa, 25, 309-325. DOI: 10.15304/ ie.25.2826. Disponible en: http://www.usc.es/ revistas/index.php/ie/article/view/2826

García-Ruiz, Rosa \& Castro-Zubizarreta, Ana (2014). Orientaciones para el desarrollo de la competencia mediática en la escuela infantil. Comunicación y Pedagogía: Nuevas Tecnologías y Recursos Didácticos, 273-274, 43-48.

García-Ruiz, Rosa; Duarte-Hueros, Ana María \& Guerra-Liaño, Sonsoles (2014). Propuesta de un instrumento de evaluación para medir el grado de competencia mediática en la etapa de educación infantil. Píxel-Bit. Revista de Medios y Educación, 44, 81-96. Disponible en: http://acdc.sav.us.es/ pixelbit/images/stories/p44/06.pdf, http://doi. org/3qv

Gozálvez-Pérez, Vicent (2013). La ciudadanía mediática. Una mirada educativa. Madrid: Dykinson.

Gubern, Román (2000). El eros electrónico. Madrid: Taurus.

Guzmán, Rosa Julia \& Guevara, Mónica (2010). Concepciones de infancia, alfabetización inicial y aprendizaje de los educadores y educadoras. Revista Latinoamericana de Ciencias Sociales, Niñez y Juventud, 8 (2), 861-872. Disponible en: http:// www.redalyc.org/pdf/773/77315155007.pdf, http://goo.gl/zRqfsl

Hernando-Gómez, Ángel \& Maraver-López, Pablo (2014). Nuevas competencias docentes para los nuevos tiempos en la educación. Comunicación y Pedagogía: Nuevas Tecnologías y Recursos Didácticos, 273-274, 59-63. 
Jenkins, Henry (2008). Convergence Culture: la cultura de la convergencia de los medios de comunicación. Barcelona: Paidós Ibérica. Disponible en: http://goo.gl/E9KFZC

Marín-Gutiérrez, Isidro; Díaz-Pareja, Elena \& Aguaded-Gómez, José Ignacio (2013). La competencia mediática en niños y jóvenes: la visión de España y Ecuador. Chasqui, 124, 41-47. Disponible en: http://rabida. uhu.es/dspace/handle/10272/7637

Marina, José Antonio (2006). Aprender a convivir. Barcelona: Ariel.

Ministerio de Educación, Cultura y Deporte, MECD (2012). Datos y cifras, Curso escolar 2012-2013. Disponible en: http://www.mecd.gob.es/ $\mathrm{dctm} / \mathrm{ministerio/horizontales/estadisticas/indicadores-publica}$ ciones/datos-cifras/datos-y-cifras-2012-2013-web.pdf?documen $\mathrm{tld}=0901 \mathrm{e} 72 \mathrm{~b} 81416 \mathrm{daf}$

Mifsud-Talon, Elvira (2012). Buenas prácticas TIC. Valencia: Generalitat Valenciana. Disponible en: http://www.ceice.gva.es/web/innovaciontecnologica/buenas-practicas-tic, http://goo.gl/hHMiTV

Morduchowicz, Roxana; Marcón, Atilio \& Camarda, Paula (2006). Los medios de comunicación en la escuela: un abordaje reflexivo, una actitud crítica. Buenos Aires: Ministerio de Educación, Ciencia y Tecnología. Disponible en: http://www.me.gov.ar/escuelaymedios/material/los_ medios.pdf

Observatorio Nacional de las Telecomunicaciones y de la Sociedad de la Información, ONTSI (2013). Informe anual sobre la sociedad en red. Disponible en: http://www.ontsi.red.es/ontsi/es/estudios-informes/ informe-anual-la-sociedad-en-red-2012-edici\%C3\%B3n-2013, http://www.ontsi.red.es/ontsi/sites/ontsi/files/informe_anual_la_ sociedad_en_red_2013_ed._2014.pdf

Pérez-Rodríguez, María Amor \& Delgado-Ponce, Águeda (2012). De la competencia digital y audiovisual a la competencia mediática: dimensiones e indicadores. Comunicar, Revista Científica Iberoamericana de Comunicación y Educación, 39, 25-34. http://doi.org/vmm. Disponible en: https://www.revistacomunicar.com/index.php?conte nido $=$ detalles\&numero $=39 \&$ articulo $=39-2012-04$

Pérez-Rodríguez, María Amor \& Delgado-Ponce, Águeda; García-Ruiz, Rosa \& Caldeiro-Pedreira, Mari Carmen (2015). Niños y jóvenes ante las redes y pantallas: La educación en competencia mediática. Madrid: Editorial Gedisa.

Prado-Aragonés, Josefina (2001). La competencia comunicativa en el entorno tecnológico: desafío para la enseñanza. Comunicar, Revista Científica Iberoamericana de Comunicación y Educación, 17, 21-30. Disponible en: http://rabida.uhu.es/dspace/bitstream/handle/10272/978/ b11903144.pdf?sequence=1, http://goo.gl/IEQIDb

Reinares-Lara, Pedro (2010). Jóvenes y televisión generalista en España. ¿Es internet responsable de una audiencia perdida? Revista de Estudios de Juventud, 88, 63-75.

Rodríguez-Rojo, Martín (2003). Didáctica general. Qué y cómo enseñar en la sociedad de la información. En El imperio de la globalización y la educación, 17-54. Madrid: Biblioteca Nueva.

Rubiano-Albornoz, Elisabel (2010). A la escucha de la infancia. Educere, 49 (14), 297-303. Disponible en: http://www.redalyc.org/articulo. oa?id=35617102006, http://goo.gl/SaLpNA

Sánchez-Carrero, Jacqueline \& Contreras-Pulido, Paloma (2012). De cara al prosumidor: producción y consumo empoderando a la ciudadanía 3.0. Icono 14, 10 (3), 62-84. Disponible en: http://www.icono14.net/ ojs/index.php/icono14/article/view/210/376, http://goo.gl/vybHo8 